\title{
PRESENTACIÓN \\ La etnohistoria en América: Crónica de una disciplina bastarda
}

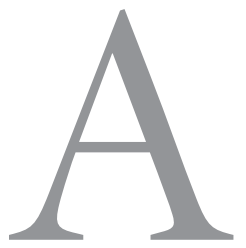

PESAR DE UN NÚMERO no despreciable de practicantes, defensores y textos esenciales propios, no es hipérbole afirmar que, en contraste con el sólido cimiento académico de la historia como disciplina, la etnohistoria sigue siendo concebida en las Américas como una novedad metodológica en el mejor de los casos, o como uno de tantos neologismos huecos en el peor de ellos. Dada la relativa diversidad analítica, teórica y temática dentro de un campo académico aparentemente formado por una serie de convergencias fortuitas entre especialistas en pos de estelas, códices, pinturas murales, textos doctrinales, relaciones de méritos, historias orales o fiestas de Corpus, las posturas en cuanto a la situación de la etnohistoria como disciplina aparte son igualmente diversas.

Para los fines de esta breve reflexión, se podrían sintetizar estas posturas en tres tendencias principales. La primera consideraría a la etnohistoria como una disciplina híbrida resultante de la convergencia de cuestionamientos antropológicos y metodologías históricas en la segunda mitad del siglo XX. La segunda concebiría la etnohistoria como una mera subdivisión de la historia, y por lo tanto, como a una pariente cercana de otras subdisciplinas - la historia social, la historia de las mentalidades, la historia cultural-que convivirían, cual Baudelaire junto a su jeune géante, como buenas hermanas a la sombra de las amplias faldas de Clío. Una tercera posibilidad — la asimilación de la etnohistoria bajo las contenciosas crinolinas de la antropología — es una solución que, aunque resulta factible para algunos arqueólogos mesoamericanistas, es frecuentemente rechazada por los etnólogos dada la distancia insondable entre textos y observaciones etnográficas.

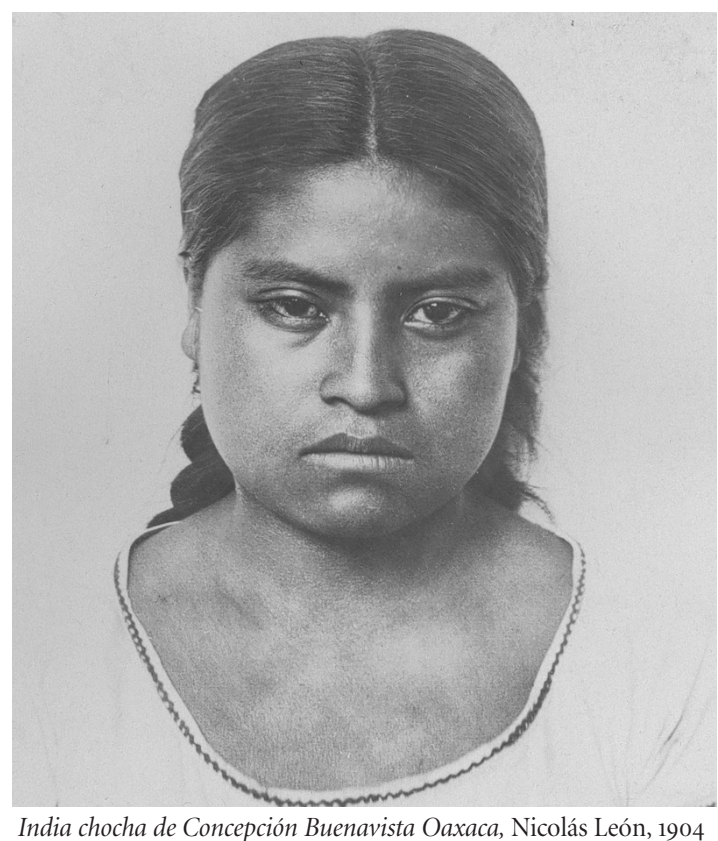


Al carecer por definición de un intercambio personal entre etnólogo e informante, la etnohistoria confrontaría un obstáculo insalvable para formar parte de la antropología.

Hay razones de peso para preferir la primera de estas tres nociones — es decir, para aducir que la etnohistoria es una empresa analítica relativamente independiente, y no otro avatar de la historia o la antropología. Sin tratar de añadir demasiado peso a una lista de argumentos que pueden consultarse por aparte, ${ }^{1}$ se podría ensayar aquí una definición de la etnohistoria mediante una serie de rasgos mínimos que la distinguen como disciplina aparte. De acuerdo con este criterio, la etnohistoria:

- Intenta analizar y reconstruir las estructuras sociales y culturales de grupos étnicos que entraron en contacto con los poderes europeos entre los siglos XV y XIX;

- Dedica particular atención al estudio lingüístico y filológico y a la contextualización histórica de textos compuestos en sistemas alfabéticos o pictográficos en lenguas no europeas;

- Enfatiza los problemas historiográficos y epistemológicos que resultan del contacto e interacción entre concepciones europeas y no europeas del pasado;

- Analiza y cuestiona la interpretación de la historia social y cultural de grupos no europeos utilizando metodologías filológicas, lingüísticas y etnológicas novedosas;

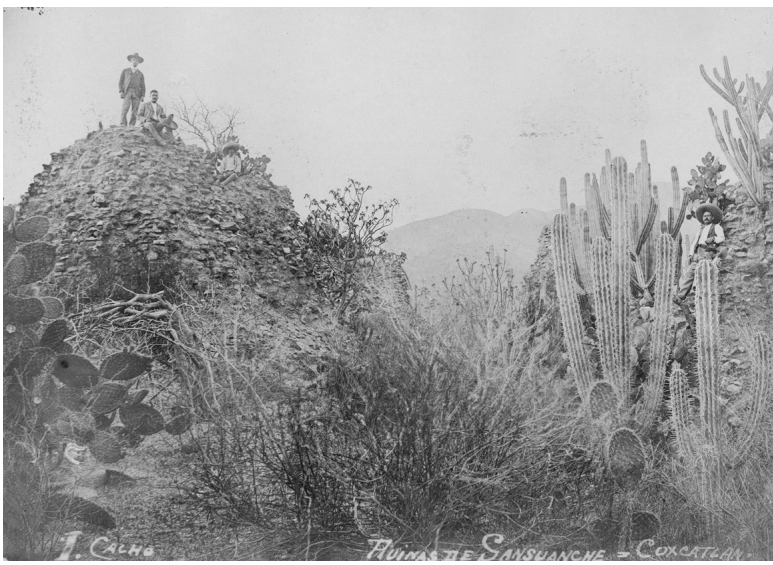

Ruinas de Sansuanche, Coxcatlán, Nicolás León, 1904

- Confronta temas que han sido tradicionalmente definidos como antropológicos estructuras simbólicas, prácticas rituales, relaciones de parentesco, etnogénesis- mediante el análisis histórico de fuentes documentales.

En realidad, estos rasgos genéricos no resuelven todos los problemas de definición de la etnohistoria, pero ofrecen un punto de referencia concreto, que contempla la praxis actual de un grupo numeroso de especialistas en la mayoría de los contextos geográficos donde se realizan investigaciones etnohistóricas en el presente - las Américas, Asia, África y Oceanía. Sin adoptar por completo la categorización antitética del mundo en grupos dominantes y dominados que propone la escuela de Subaltern Studies [Estudios Subalternos] en la India, ${ }^{2}$ podría afirmarse que los proyectos colonizadores europeos forman el inevitable punto de partida del quehacer etnohistórico.

\footnotetext{
${ }^{1}$ Por ejemplo, véase el artículo de Romero Frizzi que aparece en este número de Desacatos, así como a Chance, John K., "Mesoamerica’s Ethnographic Past", en Etnohistory, 43 (3) 1996); Krech, Shepard, "The State of Ethnohistory", en Annual Review of Anthropology, 20, 1991; y Romero Frizzi, María de los Ángeles, "Reflexionando una vez más: La etnohistoria y la época colonial", en Dimensión Antropológica, $1(1), 1994$.

${ }^{2}$ Si bien una breve mención bibliográfica no puede hacer justicia a la visión de esta escuela, podemos citar aquí por vía de ejemplo a Chakrabarty, Dipesh, "Subaltern Studies and Critique of History", en Arena 96, 1991; Chaterjee, Partha, "Caste and Subaltern Consciousness”, en Subaltern Studies VI, Oxford University Press, 1987; y a Guha, Ranajit y Spivak, Gayatri, Selected Subaltern Studies, Oxford University Press, 1985.
} 


\section{PROPUESTAS}

Dada su situación idiosincrásica como disciplina independiente, hablar de metodologías y de proyectos etnohistóricos es una tarea mucho más fácil que delinear los límites de la disciplina, presentarla como un campo de estudio unificado, o definir sus paradigmas centrales. Por este motivo, las reflexiones sobre la situación de la etnohistoria en las Américas tienden a presentar un panorama historiográfico o una reseña de problemas de investigación y publicaciones recientes.

Este número especial de Desacatos intenta asumir un tono distinto. En lugar de las pautas familiares de la reseña general, hemos preferido presentar la traducción y publicación de cinco ensayos producidos por un grupo de investigadores cuyos trabajos representan una área geográfica relativamente extensa - Mesoamérica, la India, Perú y el sureste de Estados Unidos. Estos ensayos pueden leerse como sendas respuestas a cinco temas importantes que documentan los anhelos, logros y desafíos de las primeras generaciones de especialistas que se han definido sin sonrojo como etnohistoriadores durante el último tercio de siglo. Estos temas, que se heredan a la nueva generación de etnohistoriadores que ha surgido desde el principio de los noventa, podrían definirse de la siguiente manera:

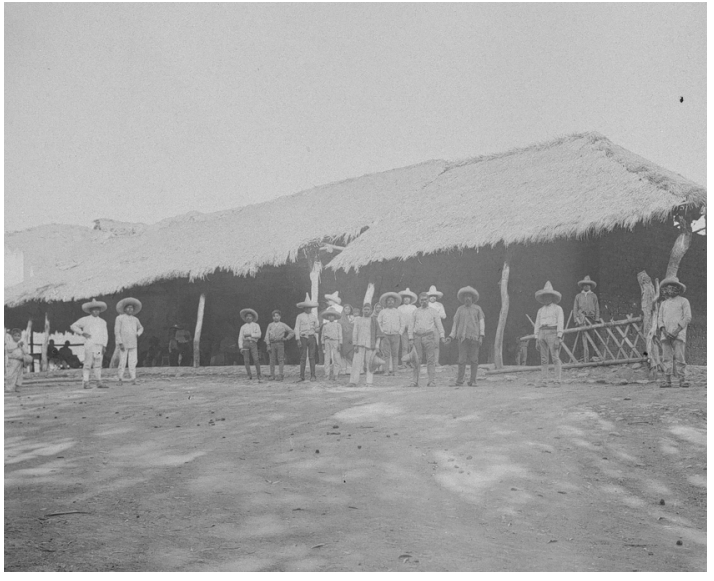

s/t, Nicolás León, 1904

\section{Antropólogos e historiadores, o el encuentro de dos mundos}

Si nos limitáramos a analizar algunas de las tendencias principales en la investigación antropológica e histórica, la tarea de combinar las perspectivas de ambas disciplinas en un mismo proyecto pudiera parecer relativamente fácil, ya que existe una pluralidad de fenómenos sociales que interesan a ambas tribus académicas. Sin embargo, de acuerdo con el retrato hablado de estas dos tribus presentado por Bernard Cohn en su artículo Un antropólogo entre los historiadores: Un informe de campo, algunos de los fenómenos sociales más relevantes y menos discutidos en torno a este encuentro de disciplinas son las amplias diferencias en el proceso de socialización, formación profesional (o déformation professionelle, si se prefiere), y adquisición de supuestos metodológicos por parte de antropólogos e historiadores. Asumiendo el papel de un etnólogo que parte a hacer trabajo de campo en la curiosa nación de los historiadores, Cohn revela, con gran agudeza e ingenio, que aun el menor diálogo entre antropólogos interesados en los archivos e historiadores fascinados por las culturas exóticas es un encuentro de dos mundos académicos y metodológicos que requiere de diestros embajadores e intérpretes.

Si bien esta contribución de Cohn fue redactada en los años sesenta, no deja de sorprendernos el hecho de que las limitaciones básicas en el diálogo entre antropólogos e historiadores descritas por Cohn siguen reproduciéndose en el mundo académico — particularmente en el ámbito anglo-americano y europeo. Aunque casi todo especialista concuerde en afirmar que la interacción metodológica entre antropólogos 
e historiadores es extremadamente provechosa y deseable, tales encuentros no siempre arrojan un resultado productivo, o aun cordial. En realidad, la incertidumbre interdisciplinaria aumenta las posibilidades de producir proposiciones abortadas y bastardos analíticos que no complacen a ninguno de sus progenitores. A pesar de estas diferencias, existen antropólogos que conciben a la etnohistoria como a una terra firma epistemológica donde se acallan las dudas posmodernistas de su disciplina, e historiadores que creen realizar investigaciones antropológicas mediante el análisis exclusivo de documentos. Esta clásica contribución de Cohn presenta, a grandes trazos, las diferencias fundamentales en la praxis de antropólogos e historiadores contemporáneos que contribuyen al desencuentro de supuestos y a la falta de consenso en torno a metodologías interdisciplinarias. Visto desde una perspectiva mesoamericanista, este diálogo interdisciplinario tal vez requiera de una Malinche o un Gaspar Antonio Chi que medie entre ambas facciones disciplinarias, con el pleno conocimiento de que algunos podrían ver tal iniciativa como una traición a una u otra disciplina académica.

\section{Notas para una etnohistoriografía crítica: eventos y procesos}

Si se concibe a la etnohistoria como una disciplina paralela y relativamente independiente de la historia, habría que postularse la construcción de un aparato crítico y metodológico que genere - como lo hace la historiografía entre los historiadores a secas - una serie de reflexiones que permitan revalorar y criticar las tendencias principales en la investigación etnohistórica. Este aparato — que podría ser llamado etnohistoriografía, por ensayar un nombre- aún está en vías de construcción, y requiere de esfuerzos que superen la reseña crítica o el ensayo bibliográfico. ¿Cuáles son los principales problemas epistemológicos que la etnohistoria confronta? ¿Cómo han sido resueltos estos problemas por corrientes, escuelas, o investigadores de gran influencia? ¿Qué cuestiones metodológicas deben seguir discutiéndose y elucidándose entre los etnohistoriadores jóvenes?

En su ensayo La etnohistoria de los eventos y de los eventos nulos, el antropólogo y etnohistoriador Raymond Fogelson

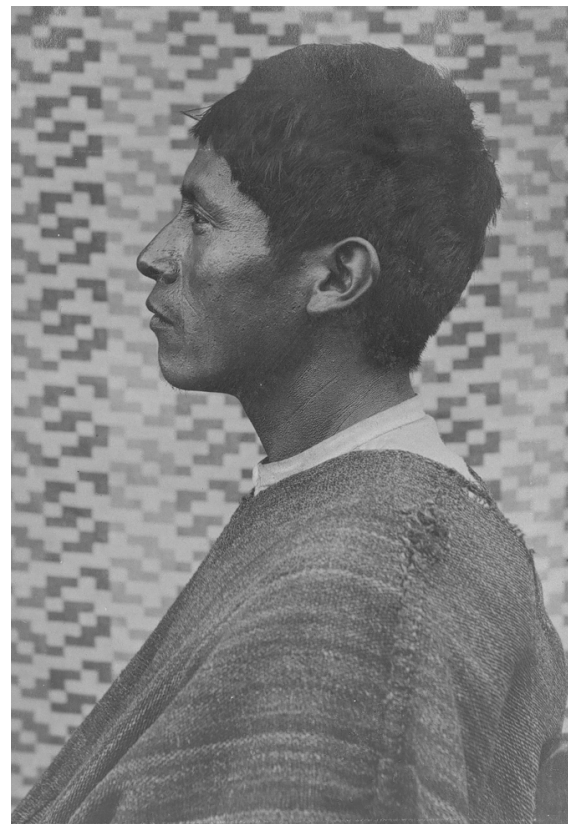

Indio de Mezontla, Nicolás León, 1904 presenta una reflexión que podría ser calificada como etnohistoriográfica sobre la percepción de eventos y procesos. Este texto — que Fogelson presentó en una conferencia magistral al final de su gestión como presidente de la Sociedad Norteamericana de Etnohistoria [American Society for Etnohistory] en 1988 - presenta un bosquejo denso, ingenioso y multifacético sobre un problema historiográfico clásico: ¿Cómo construyen los historiadores una definición general de lo que constituye un evento histórico? ¿Cuál es el papel que juegan (o dejan de jugar) las percepciones de los actores históricos en la definición de tales eventos? Su respuesta a estas cuestiones parte de un recorrido historiográfico que nos lleva de los annalistes clásicos — Lucien Febvre y Marc Bloch—a los estructuralistas más irredentos —Claude Lévi Strauss y Marshall Sahlins. 
La aportación más interesante de este ensayo es la definición que Fogelson ofrece de lo que pudiera traducirse como "evento nulo" [nonevent] en español:

Si bien los "eventos" generados por una cierta trama pueden ser construidos para fines narrativos, o para "contar un cuento", alrededor de estos eventos "reales" o fabricados se encuentra un residuo de datos culturales que tienen un interés crítico para los historiadores y los etnohistoriadores: valores, significados, símbolos, cosmologías, principios de estructuración social, y otras variables culturales sin las cuales ningún evento, real o imaginario, puede ser interpretado de forma adecuada.

En otras palabras, Fogelson rechaza una epistemología positivista o naturalista del evento —el cómodo supuesto del historiador que permitiría postular una definición infalible a priori de lo que constituye un suceso histórico. Para Fogelson, el significado histórico reside no en una narrativa o en una serie discreta de sucesos, sino en el contexto social, simbólico y estructural que permite a los miembros de diversas sociedades conmemorar (o suprimir) el pasado. Esta concepción del evento retoma una preocupación constante de la antropología - las fracturas y similitudes entre diversas categorías culturales - y resalta una vía de reflexión que está ligada íntimamente a la investigación etnohistórica.

\section{La leve esquizofrenia existencial de los etnohistoriadores}

El mito de creación dominante en la etnohistoria señala la existencia de al menos dos progenitores - Antropología e Historia - que procrean aquella disciplina de manera furtiva, y la abandonan en las selvas escolásticas, cual bastarda indeseable. Esta condición de ilegitimidad — que puede inspirar una esquizofrenia existencial entre los etnohistoriadores - procede de un posible doble rechazo de la etnohistoria por parte de dos disciplinas sólidamente institucionalizadas. Por una parte, algunos antropólogos rechazan la investigación etnohistórica como una forma parcial e indirecta de investigar problemas antropológicos sin ensuciarse las manos o utilizar presupuestos considerables — como lo hacen los arqueólogos — o sin arriesgar la salud física y emocional en un pueblo remoto - como

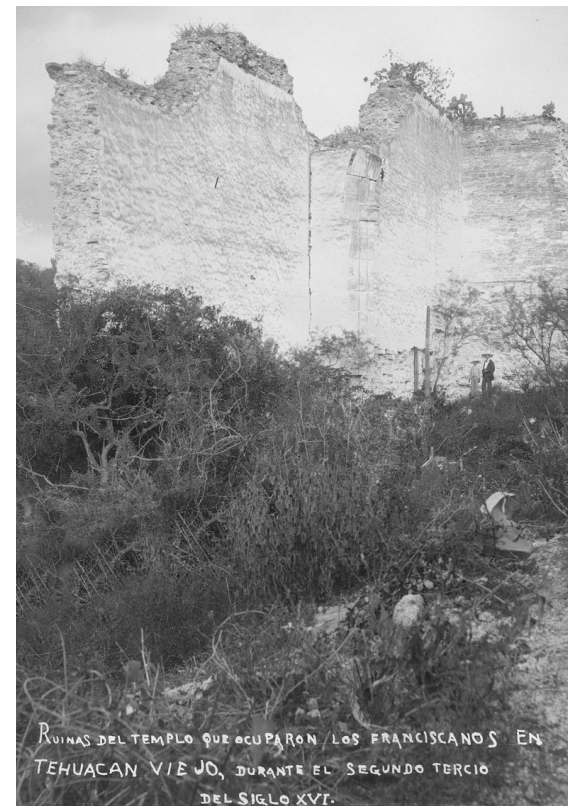

Ruinas del templo que ocuparon los franciscanos en Tehuacán viejo, siglo XVI, Nicolás León, 1904 lo hacen los etnólogos. Por otra parte, la visión analítica intensa, contextual y circunspecta de la etnohistoria puede ser criticada como incompleta por aquellos especialistas que escriben Historia con la hache mayúscula de Tucídides. En ambos casos, la etnohistoria quedaría relegada a una posición institucional secundaria.

Esta crisis existencial no es un simple caso de esquizofrenia o confusión metodológica: la posición institucional de la etnohistoria como disciplina sigue siendo un tanto incierta. A pesar de un número creciente de especialistas dispuestos a llamarse etnohistoriadores, esta disciplina cuenta con un número mínimo de espacios institucionales en el organigrama académico de Norteamérica. En México —un país donde el interés por las culturas mesoamericanas es un aliado constante de la etnohistoria- existen programas de 
licenciaturas con una fuerte tendencia etnohistórica en la Escuela Nacional de Antropología e Historia y en la Universidad Autónoma de Yucatán, así como un grupo relativamente substancial de etnohistoriadores en el Instituto de Investigaciones Antropológicas de la UNAM y en las diversas sedes del Centro de Investigaciones y Estudios Superiores en Antropología Social (CIESAS). En Estados Unidos — donde la competencia interdisciplinaria asume rasgos hobbesianos- existen programas de antropología o historia latinoamericana en las universidades de Albany, California (Los Ángeles), Chicago, Michigan, Pennsylvania, Tulane, Vanderbilt y Wisconsin (Madison), donde un etnohistoriador puede formarse, siempre y cuando se resigne a presentarse profesionalmente ya sea como antropólogo o como historiador, asumiendo que pueda encontrar un puesto académico. Finalmente, el número de publicaciones donde proliferan contribuciones caracterizables como etnohistóricas es reducido — podríamos mencionar aquí a Desacatos, Dimensión Antropológica, Estudios de Cultura Maya, Estudios de Cultura Náhuatl y a Colonial Latin American Review, Ethnohistory e History and Anthropology, en el ámbito académico anglonorteamericano.

En el artículo titulado La historia es una, la etnohistoriadora María de los Ángeles Romero Frizzi examina la crisis de identidad de los etnohistoriadores desde una perspectiva mesoamericanista. Iniciando con una exploración del tema paralelo de las apologías sobre el quehacer histórico, Romero Frizzi examina una serie de trabajos mesoamericanistas que contienen, si las nuevas generaciones de etnohistoriadores desean leerlos de tal manera, una guía implícita para el desarrollo de nuevos objetivos de investigación. Estos

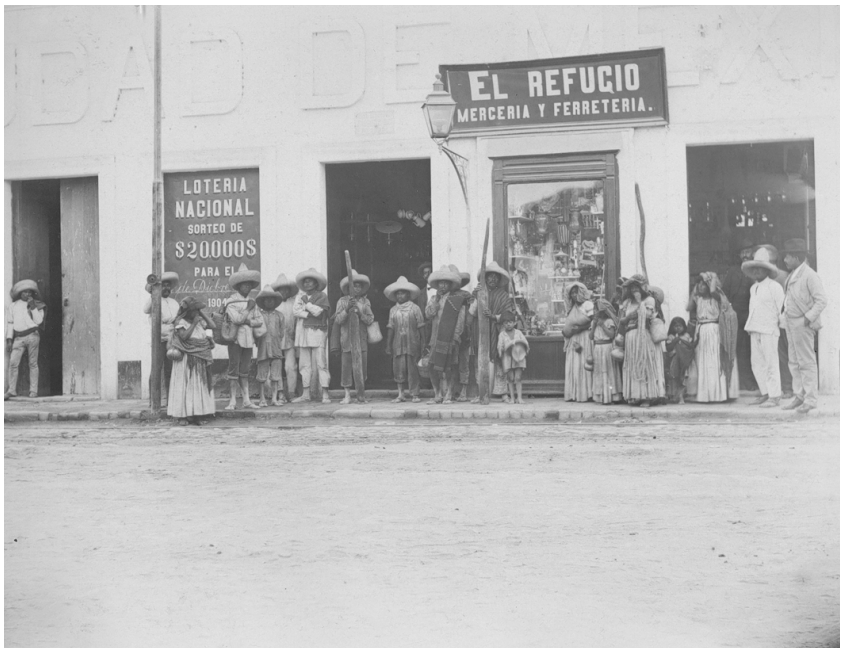

Grupo de indios popolocas de Atzingo, Nicolás León, 1904 encuentros pragmáticos con las fuentes documentales ofrecerían a los etnohistoriadores jóvenes una manera substancial y metódica de definirse como miembros de una disciplina. Asimismo, Romero Frizzi presenta las estrategias de dominio colonial como el hecho histórico central e inexorable que define, para bien o para mal, el campo de acción empírico de la etnohistoria.

Por otra parte, Romero Frizzi presenta la existencia providencial de fuentes históricas en diversas lenguas y sistemas de escritura mesoamericanos como un punto ontológico de referencia absolutamente indisputable. Parafraseando a una célebre crítica del funcionalismo estructural británico, podríamos afirmar que la etnohistoria será el estudio de fuentes en lenguas indígenas, o no será nada. Al reconocer esta realidad metodológica, Romero Frizzi sugiere: la crisis existencial del etnohistoriador desaparece, dando paso, a su vez, a un eterno cuestionamiento epistemológico y metodológico sobre el modus operandi de los etnohistoriadores, al confrontar textos alfabéticos o pictográficos mesoamericanos dentro de un contexto histórico colonial complejo, en el que las divisiones entre indígenas y no indígenas pueden obscurecer nuestra percepción de ciertos fenómenos culturales. En otras palabras, esta leve esquizofrenia que aqueja a los etnohistoriadores no requiere de soluciones draconianas, sino de una labor pragmática constante y reflexiva. 


\section{El problema del historiador autóctono o la etno-etnohistoria}

El término "etno-etnohistoria" ha sido utilizado con anterioridad por los antropólogos norteamericanos Raymond Fogelson y Terry Turner para referirse, de manera un tanto lúdica, al problema que los etnohistoriadores formados en el mundo académico profesional encuentran al confrontar, de manera implícita o explícita, la conciencia histórica de los historiadores locales dentro de un grupo étnico o social bajo estudio. ${ }^{3}$ Sin importar el término que se utilice para expresar esta confrontación, surgen aquí al menos dos preguntas dignas de consideración. Si los etnohistoriadores académicos generalmente poseen el trasfondo cultural de una nación-

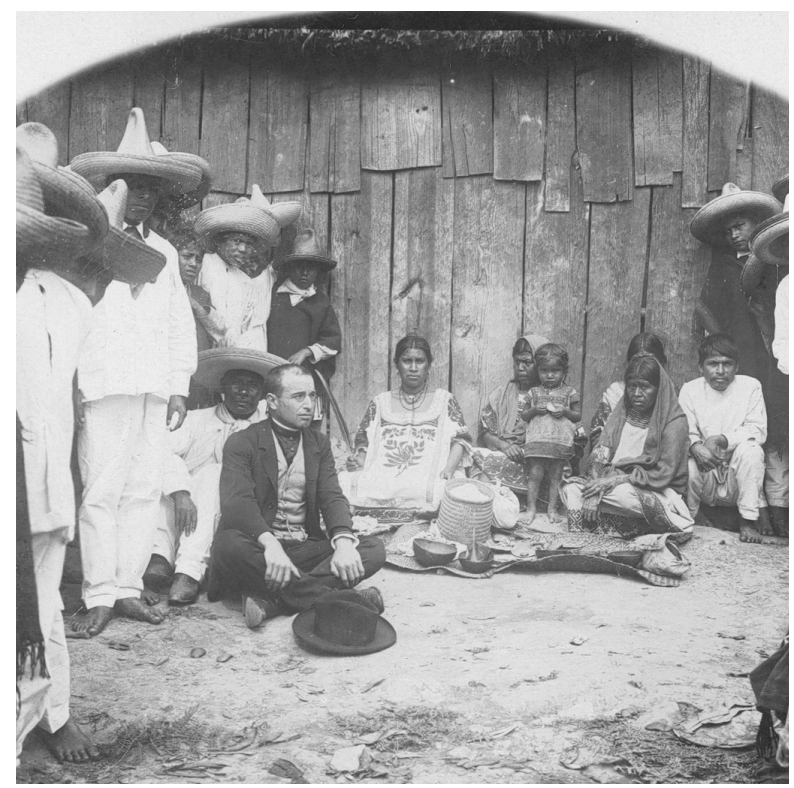

s/t, Nicolás León, 1904 estado occidental y realizan operaciones de traducción al examinar el pasado de una cultura ajena, ¿podemos llamar etnohistoriadores a los intelectuales autóctonos que investigan su propia cultura? ¿Hay manera de conciliar las disonancias entre la interpretación autóctona de un pasado reclamado como propio y la labor sistemática pero foránea del etnohistoriador?

Para los americanistas, éste es un problema que surge desde el momento en que Chimalpahin, Tezozómoc o Guaman Poma toman la pluma para recopilar una narrativa histórica obstinadamente localista y autóctona en caracteres alfabéticos. Si bien estos ensayos históricos (o etno-etnohistóricos) son emblemáti$\cos \mathrm{y}$, desde nuestra perspectiva, extraordinariamente innovadores, el problema reside en su representatividad. No es posible tomar las obras de estos autores como la expresión uniforme de una conciencia histórica indígena, y es preciso reconstituir los diversos contextos políticos y sociales en los que surgen sus aserciones más vehementes.

En una colaboración titulada Una etnohistoria poco étnica: Nociones de lo autóctono en una comunidad campesina peruana, Frank Salomon propone un aggiornamiento de este viejo problema, que ya había examinado desde un punto de vista historiográfico en otra colaboración reciente. ${ }^{4}$ Su punto de partida es la observación de que, a pesar del grave peso de una historia incaica y colonial en los Andes, algunas comunidades campesinas definen su identidad local con base en una ruptura sísmica con dicho pasado. Esta ruptura sugiere que existen una serie de tensiones y rupturas entre la noción del historiador indígena colonial y la interpretación propia que un historiador peruano local hace de ciertos documentos coloniales que documentan la historia de su comunidad.

\footnotetext{
${ }^{3}$ Véase Fogelson, Raymond, “On the Varieties of Indian History: Sequoyah and Traveller Bird”, en Journal of Ethnic Studies, 2, 1974; y Turner, Terence, "Ethno-Ethnohistory", en Rethinking History and Myth, University of Illinois Press, 1988.

${ }^{4}$ Nos referimos a "Testimonies: The Making and Reading of Native South American Historical Sources", en Cambridge History of the Native Peoples of the Americas, vol. 3, parte 1, South America, Cambridge University Press, 1999.
} 


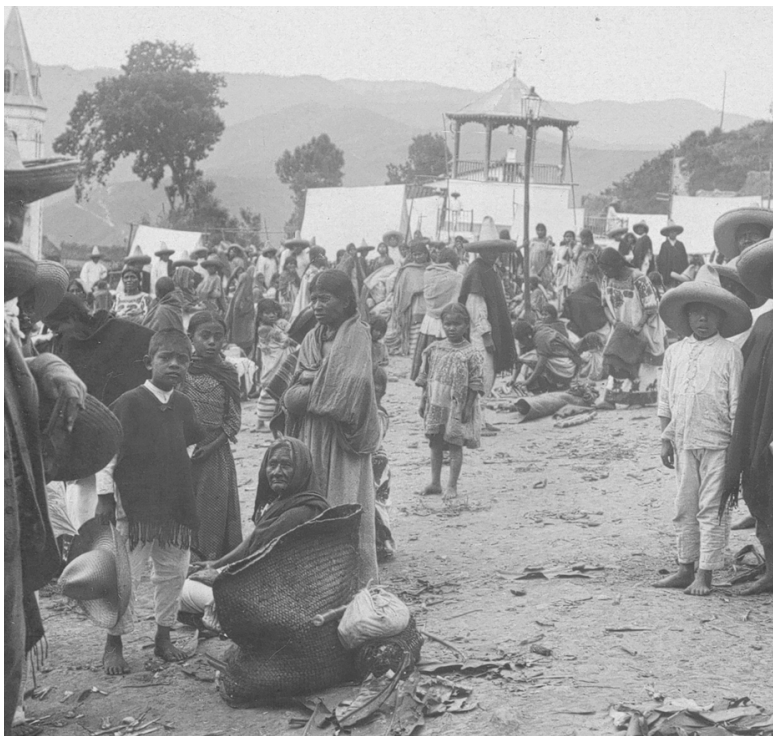

s/t, Nicolás León, 1904
El interés de Salomon por demostrar la complejidad de una definición autóctona de identidades locales lo lleva a explorar una cuestión cardinal: las diversas y contrastantes interpretaciones del pasado que pueden emanar de una misma fuente, cuando ésta es leída por un historiador autóctono y un académico foráneo. Salomon explica esta divergencia mediante un contraste entre una transcripción autóctona del documento -que lucha por permanecer fiel a una serie de convicciones locales sobre la hegemonía colonial- y una transcripción "académica", realizada por él mismo.

Salomon intenta, si no conciliar, al menos respetar la ambigüedad epistemológica que emana de estas interpretaciones encontradas. Por lo tanto, este investigador presenta algunas nociones locales del proceso de formación de identidades colectivas como el contexto que explica y presta validez a una transcripción que hubiera sido calificada como incompleta o errática por un historiador tradicionalista. Esta operación no es un contextualización de narrativas históricas localistas. De esta manera, Salomon nos hace tomar la medida del abismo entre nuestras percepciones y métodos historiográficos como etnohistoriadores foráneos, y las interpretaciones multifacéticas y heterodoxas de los historiadores autóctonos, que pueden contener afirmaciones epistemológicas en lo que pudiera aparecer a simple vista como un tropiezo semántico.

\section{Las fuentes en lenguas mesoamericanas y la "nueva filología" estadounidense}

No se puede negar el efecto que han tenido los intereses de investigadores europeos y norteamericanos en el desarrollo de una preocupación etnohistórica propia en América Latina. Es innegable que la edición Kinsborough del Códice Mendoza, los trabajos de Ternaux-Compans y Brasseur de Bourbourg, y la Conquista de México de William H. Prescott —el best-seller que algunos miembros de las fuerzas invasoras norteamericanas cargaban en sus alforjas en 1847- compelieron a investigadores como José Fernando Ramírez, Joaquín García Icazbalceta, Nicolás León y Luis González Obregón a revalorizar la historia social y cultural de grupos indígenas y a buscar vías metodológicas innovativas para analizar el pasado prehispánico y colonial de las Américas a finales del siglo XIX. Más adelante, durante las décadas de 1930 y 1940 —años que vieron nacer los primeros trabajos sobre Mesoamérica donde la etnohistoria comienza a reconocerse como una empresa intelectual disciplina aparte- las investigaciones de Alfonso Caso, Wigberto Jiménez Moreno, Paul Kirchoff, Robert Ricard, Ralph Roys y Frances Vinton Scholes empiezan a abrir espacios para una nueva visión disciplinaria tanto en México como en Estados Unidos. De hecho, la preocupación constante de las siguientes generaciones de investigadores norteamericanos y franceses 
por temas etnohistóricos mexicanos — reflejada en los trabajos de Woodrow Borah, François Chevalier, Howard Cline, Charles Gibson, Richard Greenleaf, y Donald Robertson en las décadas de los cincuenta y los sesenta - estimula el análisis de dichos temas en Latinoamérica aun entre los especialistas que se definen tajantemente como historiadores o antropólogos.

A partir de la década de los treinta, el estudio de fuentes coloniales con textos en náhuatl, maya yucateco, zapoteco, otomí, y otras lenguas mesoamericanas empieza a emerger como una temática de investigación especializada dentro de la investigación etnohistórica. Por supuesto, dicho estudio se apoya en el trabajo inicial de recopilación bibliográfica y análisis preliminar realizados por especialistas como José $\mathrm{F}$. Ramírez, Joaquín García Icazbalceta, Francisco del Paso y Troncoso y Eduard Seler. Sin embargo, hay que señalar dicha década como un período fructífero en el que Ángel María Garibay K. y Walter Lehmann publican traducciones de textos nahuas, Ralph Roys inicia la publicación de fuentes en maya yucateco, Jiménez Moreno examina fuentes pictográficas y alfabéticas zapotecas, y Jacques Soustelle presenta sus traducciones de canciones y cuentos en otomí. Estos esfuerzos continúan durante los cuarenta y cincuenta, gracias a las contribuciones de los especialistas ya nombrados, aunados a los trabajos de Robert Barlow, Alfredo Barrera Vásquez, Heinrich Berlin y Adrián León.

Hacia finales de la década de los sesenta — gracias a un número no despreciable de traducciones de textos indígenas coloniales realizadas por Arthur Anderson y Charles Dibble, Fernando Horcasitas, Miguel León Portilla, Alfredo López Austin, Luis Reyes García y Günter Zimmermann — se puede afirmar que el centro de gravedad en esta corriente etnohistórica corresponde al Valle de México y a otras áreas de habla náhuatl. Por lo tanto, no es sorprendente que esta orientación geográfica y lingüística haya cautivado el interés de un grupo de especialistas, estadounidenses en su mayoría, que crean una corriente novedosa en el mundillo relativamente conservador de los historiadores norteamericanos, dedicada al estudio sistemático de todo tipo de fuentes coloniales en lenguas mesoamericanas.

De acuerdo con el análisis de Matthew Restall en su artículo Filología y etnohistoria: Una breve historia de la "nueva filología" en Norteamérica, esta corriente —autodenominada como "nueva filología" [New Philology] — surge a mediados de los años setenta gracias a los esfuerzos de un grupo académico bajo el liderazgo de James Lockhart, ahora profesor emérito de historia en la Universidad de California en Los Ángeles. Debe reconocerse aquí que, en contraste con la cooperación y comunicación que existiera entre el reducido grupo de especialistas mexicanos y estadounidenses dedicados a este tema desde los años treinta hasta los sesenta, la "nueva filología" responde a las condiciones de trabajo e investigación del mundo académico estadounidense de los años setenta y ochenta. Es por ello que, si bien los trabajos de la "nueva filología" coinciden en ciertas vertientes con las publicaciones del Seminario de Cultura Náhuatl de la UNAM - para nombrar una corriente afín en México- sigue existiendo una comunicación limitada entre las corrientes etnohistóricas mexicanas y estadounidenses contemporáneas.

El ensayo de Restall intenta presentar un bosquejo bibliográfico y metodológico de la nueva filología norteamericana. Dado el número apreciable de publicaciones en lengua inglesa producido por los simpatizantes de esta corriente, nos parece interesante y útil reflexionar sobre la emergencia y desarrollo de una escuela que, a pesar de tener a Mesoamérica como objeto de estudio, está firmemente anclada en un contexto académico foráneo que presenta muchas diferencias con la labor académica en Latinoamérica. Como miembro del gremio de los nuevos filologistas, Restall ofrece una visión interna del desarrollo de esta corriente y define las contribuciones particulares de esta escuela al quehacer etnohistórico. Consideramos que esta perspectiva podría contribuir al desarrollo de un diálogo más directo entre los etnohistoriadores latinoamericanos y estadounidenses. 


\section{REFLEXIONES}

Si bien las cinco proposiciones anteriores no son asimilables dentro de una reflexión general, podríamos bosquejar aquí, en vez de una conclusión, un acercamiento a un tema que aparece en las colaboraciones ya citadas, y que sigue siendo de gran interés para los etnohistoriadores: la relación entre el contexto de producción de las fuentes coloniales y la madurez de la etnohistoria como empresa intelectual independiente.

Dado el papel central de la subyugación colonial en la historia de las Américas, lo que ahora llamamos etnohistoria tiene un pasado cruento y aciago. No es posible presentar la etnohistoria como una disciplina que surge en un estado de completa madurez, como Pallas Atena del cráneo de Zeus, en plena mitad del siglo XX. Resulta mucho más sensato argüir que la etnohistoria surge de una temática y una metodología preexistentes en la historiografía de las Américas. Desde este punto de vista, la etnohistoria heredaría, de una manera consciente, crítica y sistemática, una serie de preguntas, temas y modos de operación que existían avant la lettre en el quehacer histórico americano del período colonial y durante la emergencia de las naciones-estado americanas en el siglo XIX. ¿Deberían entonces redefinirse como etnohistóricas ciertas preguntas planteadas por Cieza de León, Sahagún, Valadés, Chimalpahin, Guaman Poma, Torquemada, Cobo o Clavijero? O tal vez, si los historiadores arguyeran que lo anterior raya en el anacronismo, debería hacer esta pregunta de manera inversa: ¿Es en los textos de estos cronistas que se encuentra el germen de una disciplina que ahora se reconoce como tal y que apenas inicia el reconocimiento de su trayectoria?

Sin hacer pronunciamientos dramáticos, quisiéramos formular aquí una sugerencia simple pero polémica. Al reconocer la etnohistoria como disciplina aparte, sus practicantes deben absorber el peso de una tradición historiográfica que proviene de proyectos coloniales cuyas aristas más agudas siguen incidiendo de manera sutil aun en la recolección más inocente de datos lingüísticos o etnográficos presentados por las fuentes coloniales. No profesamos la creencia de que el pasado, como sugieren algunos, ${ }^{5}$ pueda ser descolonizado: la etnohistoria no es un laboratorio cognoscitivo donde puedan separarse las intenciones de los diversos autores de textos coloniales de un substrato indígena puro y verdadero mediante la alquimia de las palabras. Desafortunadamente, es dudoso que esta absorción de un pasado complejo, contencioso y mal comprendido resulte en el surgimiento de una escuela etnohistórica que pueda complacer a todo tipo de tendencias políticas y sociales. Debemos estar preparados para una etapa de madurez en el que la etnohistoria pueda arrojar resultados contenciosos y divisivos, sin que esto amenace su solidez epistemológica.

David Eduardo Tavárez

coordinador

CIESAS-DF
Kimbra Smith

subcoordinadora

Universidad de Chicago

\footnotetext{
${ }^{5}$ Véase, por ejemplo, el análisis de la obra de Guaman Poma presentado en Adorno, Rolena, Guaman Poma: Writing and Resistance in Colonial Peru, University of Texas Press, 1986.
} 